Colloque C2, suppl. au Journal de Physique II, Vol 1, septembre 1991

\title{
ELECTRON SIGNIFICANCE TO DIAMOND SYNTHESIS IN PLASMA ENHANCED CVD PROCESS
}

\section{S.F. MITURA}

Institute of Materials Science and Metals Technology, Technical University of £бdź, Zwirki 36, 90-924, £б́dz, poland

Abstract-The role of electrons in the process of diamond synthesis in radio frequency hydrocarbon plasma has been shown. Polycrystalline diamond films were grown when electrons from an independent source were used. Without the electrons the amorphous carbon films were observed.

1.- Introduction.

The diamond creation from the gaseous phase under a reduced pressure with the plasma fraction process has been known for over twenty years $|1|$. However in spite of a large amount of research work which has been carried out in many scientific centres, some questions concerning the role of different diamond nucleation and growth activators have not been answered yet. Dne of these questions refers to the influence of electrons particularly in the first phase of the diamond low - pressure synthesis.

As there are methods of diamond creation under reduced pressure without plasma fraction, i.e. without electrons $|2|$, one should think that the electrons role is connected with an acceleration of the diamond nucleation process. In the other case, a significant role is played by electrons activating states on the substrate and crystalite surfaces which are suitable for the growth of diamond phase in the plasma methods. Matsumoto $|3|$ reported on diamond growth in an rf PA CVD combined with a hot filament to improve on the diamond growth rates. Sawabe and Inuzuka $|4|$ later developed an electron assisted CVD method for growing diamond. 
Recently Mitura, Has and Gorochovsky |5| used the hybrid rf magnetron method with a gas ionization independent electron source based on the dc arc principle.

2.-Experimental.

The method of hydrocarbon decomposition in if plasma with dc biased hot filament was used. Fig.l shows the apparatus for carbon deposition.

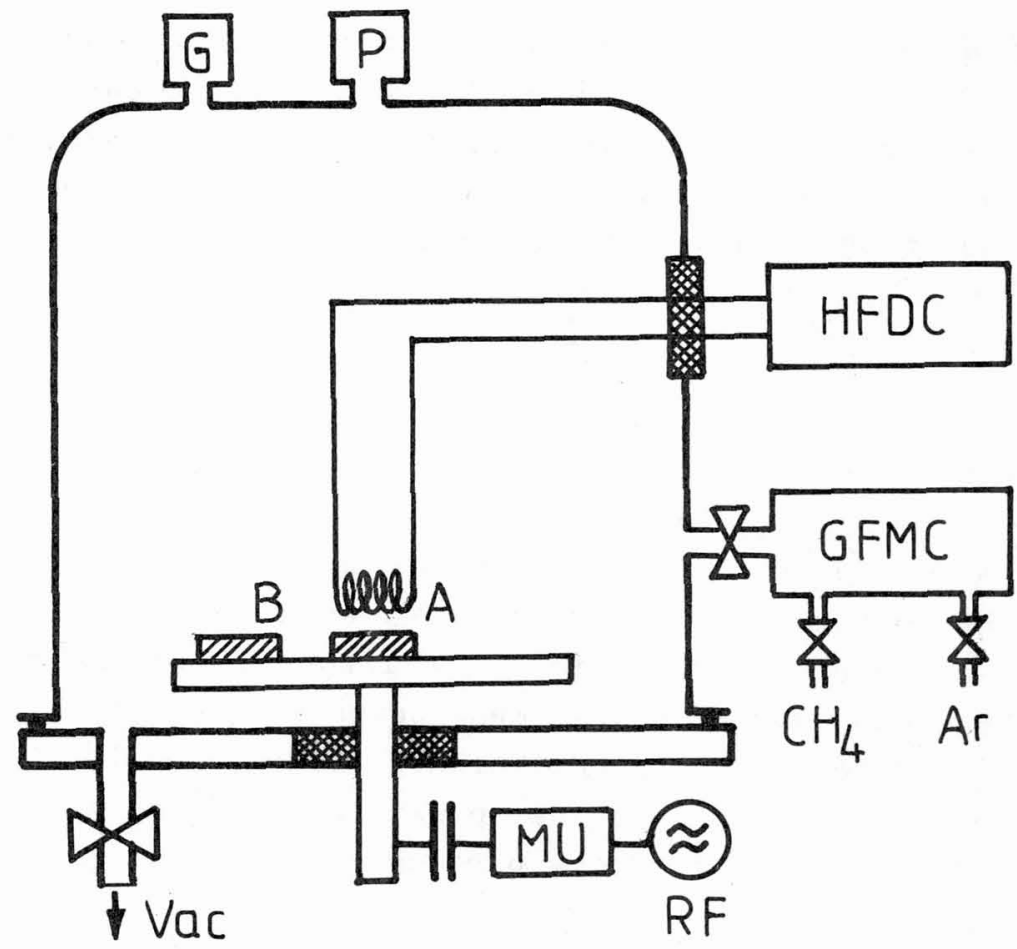

Figure 1. The apparatus for diamond synthesis by hf rf CVD method. RF -27.12 MHz generator, MU - matching unit, HFDC - hot filament with direct current bias power supply, GFMC - gas feeder with a microcomputer control, $P$ - pyrometer, $G$ pressure gauge, $A$ and $B$ - position of substrates.

The silicon substrates were placed in two positions: A - below the wolfram filament, and $B$ - at a long distance from the hot filament. During deposition the silicon wafers were subjected to intensive water-cooling, their temperature did not exceed $450 \mathrm{~K}$. 
The difference between this plasmachemical reactor and the first one we used in our experiments $|6|$ consists first of all in the use of hot filament with additional direct current negative biasing of the hf electron source. The deposition parameters used in the work reported here are listed in table $I$.

\begin{tabular}{ll}
\hline Substrates & silicon \\
Frequency & $27.12 \mathrm{MHz}$ \\
Gas & methane \\
Pressure & $50 \mathrm{~Pa}$ \\
Gas flow & $\sim 15 \mathrm{sccm}$ \\
Filament temperature & $\sim 2200 \mathrm{~K}$ \\
Negative self-bias of rf electrode & $200 \mathrm{~V}$ \\
Negative dc bias of hot filament & $200 \mathrm{~V}$ \\
Growth rate & $\sim 0.5 \mu \mathrm{m} / \mathrm{h}$ \\
Filament-to-substrate distance & $15 \mathrm{~mm}$ \\
\hline
\end{tabular}

Table I.-Growth conditions of hot filament rf: CVD of diamond films. The full detailed analysis of the system is to be reported $|7|$. After deposition the following measurements were performed:

- structural investigations with transmission electron microscope(TEM)

- ellipsometrical measurements with He-Ne laser light at $\lambda=628.8 \mathrm{~nm}$

\section{3. -Results.}

For structural investigations specimens with films deposited on their surfaces were prepared in the way described earlier.|6|. Surfaces of silicon wafers were dissolved partly in diluted hydrofluoric acid, rinsed with distilled water, leaving films which were transferred onto microscopic mesh.

TEM investigations of thin films carried out using hf $r f$ CVD indicate that the films obtained in position $A$ are crystalline. All kinds of carbon allotropic forms were observed. The degree of crystallinity and the type of carbon forms obtained are dependant on the distance from hf source and on the dc and rf bias voltage. 
Figure l shows a diffraction pattern and corresponding bright - and dark - field micrographs of diamond films that were produced by hot filament rf CVD technique.
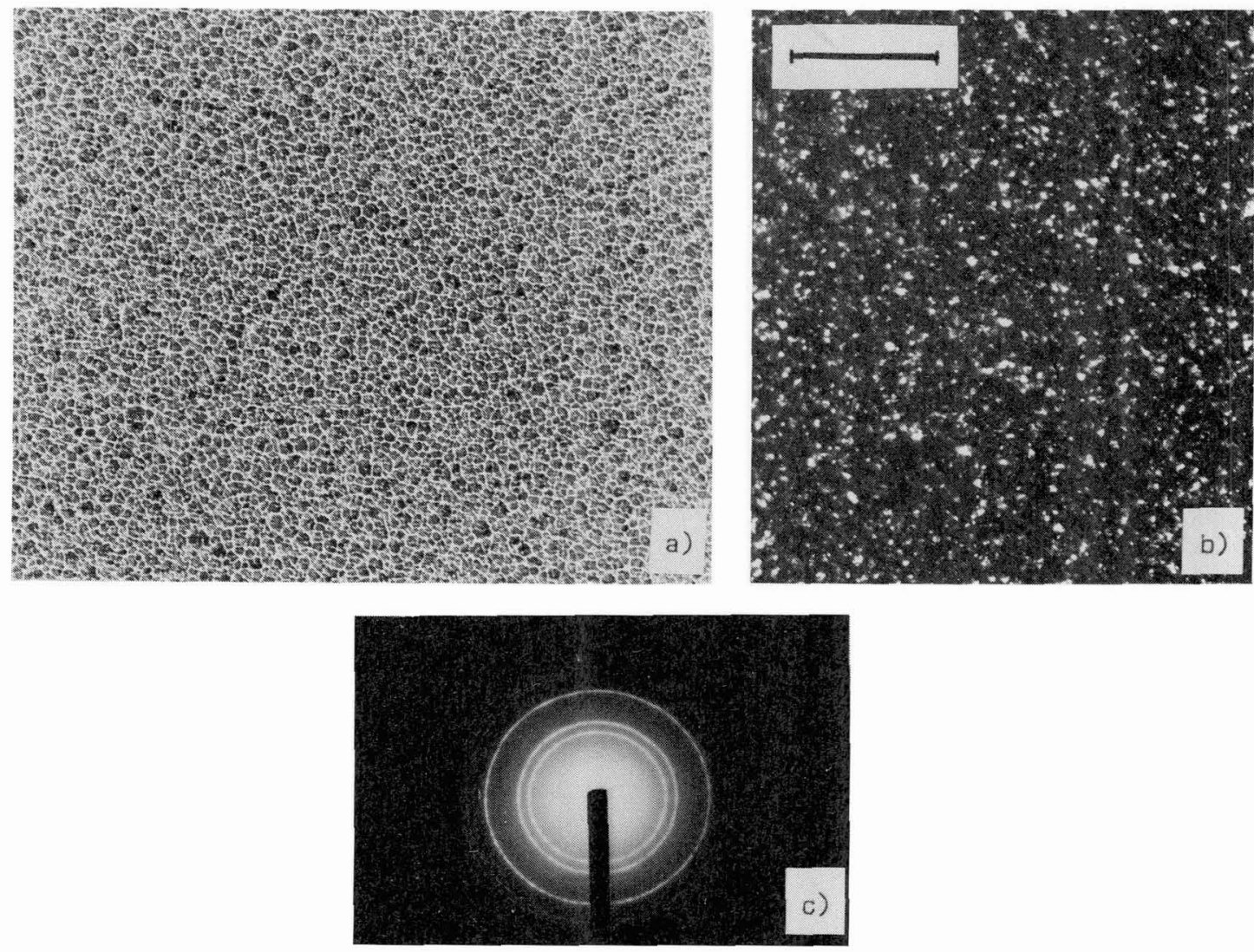

Figure 2.-TEM micrographs of diamond film in bright field (a), dark field (b), and corresponding electron diffraction pattern (c) Marker represents $0.5 \mu \mathrm{m}$.

The interplanar spacings calculated from electron diffraction pattern are in very good agreement with the reported value of cubic diamond. The presence of forbidden reflection in the diffraction patterns of thin diamond films have been commonly attributed to cubic diamond $|8|$. The observed interplanar spacings and reported values (ASTM 6-675) are shown in table II.

On the other hand, the films which were obtained in the $B$ position (figure I) are predominantly amorphous. 


\begin{tabular}{cccccc}
\hline $\begin{array}{c}\text { Observed } \\
d|n m|\end{array}$ & 0.21 & 0.18 & 0.13 & 0.11 & 0.09
\end{tabular}

$\begin{array}{cccccc}\begin{array}{c}\text { Reported } \\ \mathrm{d}|\mathrm{nm}|\end{array} & 0.206 & 0.178^{*} & 0.126 & 0.107 & 0.089\end{array}$

(hkl)

111

200

220

311

Table II.-The observed interplanar spacings and reported values.

*Value is calculated from $a_{0}=0.3567 \mathrm{~nm}$.

There have been led ellipsometric measurements. The results, showed in the table III, indicate, additionally, that the films which have been obtained on the substrates placed between the hot filament and $\mathrm{r}$ electrode are diamond and that those placed away from the filament are diamondlike.

The films on the substrate $A$

The films on the substrate $B$

Table III. The refractive indexes for the films obtained on the $A$

and B substrates.
and $\mathrm{B}$.

\subsection{8}

1.95

4.-Discussion.

A carbon atom can form two covalent bonds at the expense of the unpaired electrons present in it. Characteristic for carbon are the compounds and forms in which each of its atoms is bound to the neighbouring ones by means of four covalent bonds. This is possible owing to the fact that when a certain amount of energy is used, one of the 25 electrons in an atom can be transferred to the $2 p$ sublevel. As a result, the atom passes over to an excited state, and the number of unpaired electrons grows. Such a process of excitation follows:

$$
\text { C }\left(2 s^{2} 2 p^{2}\right) \longrightarrow C^{*}\left(2 s^{4} 2 p^{3}\right)
$$

where $E$ is energy transmitted, due to collisions of electrons and photons with the gas molecules. 
Now the outer electron layer of the carbon atom contains four unpaired electrons. Consequently, an excited carbon atom can participate in the formation of four covalent bonds.

The increase in the number of covalent bonds produced is attended by the liberation of greater amount of energy that is used by the atom for different excited states $|9|$.

The electrons activating appropriate states in the carbon atoms to produce $s \mathrm{p}^{3}$ interatomic bonds cause that the polycrystalline diamond films may be deposited during rf decomposition of hydrocarbons with addition of electrons from the hot filament source.

There are known works on the synthesis processes activation with electrons assistance $|3,4,10|$ and with photons participation $|12|$. Though in this work one cannot disclude the thermal excitation participating, it seems to be confirmed that the influence of electrons is proved. The results of experiments with additional polarisation of the electron source to the potential at least equal the negative self-bias potential of $\mathrm{r}$ electrode show the existence of the diamond synthesis process.

In $r f$ decomposition of hydrocarbons only amorphous carbon films or the films with crystalline deposits which were formed in the gas phase during the plasmachemical reactions with the electron fraction were performed $|11|$.

5.-Conclusions.

It is possible to obtain the diamond thin films without hydrogen addition and at low temperature of substrates. The diamond synthesis in hf rf CVD take place owing to electrons from wolfram hot filament.

References.

11 AISENBERG S., CHABOT R., J.Appl.Phys., 42(1971) 2953.

2) SPITSYN B.V., BOUILOV L.L., DERYAGIN B.V., J.Crystal Growth, 52(1981)219.

3 MATSUMOTO S., J.Mater.Sci Lett., 4(1985)600.

4 SAWABE A., INUZUKA T., Thin Solid Films, 137(1986)89.

51 MITURA S., HAS Z., GOROCHOVSKY V., in: MATTHEWS A., BACHMANN P. (eds.), Proc. First Europ. Conf. "Diamondlike and Diamond Films", Crans-Montana, Switzerland, Sept1991

61 HAS Z.,MITURA 5., Thin Solid Films, 128(1985)353.

17 MITURA S., to be publ. in Surf. Coat. Technology.

8) VORA H. MÓRAVEC T.J., J.Appl.Phys., 52(1981)6151.

9) GLINKA N.L., General Chemistry, Mir Publ.Moscow, Moscow, 1990, vol. I, p.133.

10I FABISIAK K., ORZESZKO S., ROZPLOCH F.,High Temperatures-High Press., 22(1990)177.

11) MITURA S., J.Crystal Growth, 80(1987) 417.

12 SCHEIBE H.-J., SIEMROTH P.,POMPE W., SCHOENEICH B., in: as before- $|5|$.

This work was supported by the Polish Government Grant No. DNS - T/10/065/90-2. 